\title{
Relationship between In Vivo Receptor Occupancy and Efficacy of Metabotropic Glutamate Receptor Subtype 5 Allosteric Modulators with Different In Vitro Binding Profiles
}

\author{
Jerri M Rook', Mohammed N Tantawy $y^{2,3}$, Mohammad S Ansari ${ }^{3}$, Andrew S Felts', Shaun R Stauffer ${ }^{1,4}$, \\ Kyle A Emmitte ${ }^{1,4}$, Robert M Kessler ${ }^{5}$, Colleen M Niswender', J Scott Daniels', Carrie K Jones', \\ Craig W Lindsley ${ }^{1,4}$ and P Jeffrey Conn ${ }^{*, 1}$
}

'Department of Pharmacology and Vanderbilt Center for Neuroscience Drug Discovery, Vanderbilt University Medical Center, Nashville, TN, USA;

${ }^{2}$ Vanderbilt University Institute of Imaging Sciences, Nashville, TN, USA; ${ }^{3}$ Department of Radiology and Radiological Sciences, Vanderbilt

University Medical Center, Nashville, TN, USA; ${ }^{4}$ Department of Chemistry, Vanderbilt University Medical Center, Nashville, TN, USA;

${ }^{5}$ Department of Radiology, University of Alabama, Birmingham, AL, USA

\begin{abstract}
Allosteric modulators of the metabotropic glutamate receptor subtype 5 ( $\mathrm{mGlu}_{5}$ ) have exciting potential as therapeutic agents for

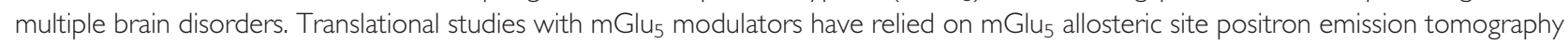
(PET) radioligands to assess receptor occupancy in the brain. However, recent structural and modeling studies suggest that closely related $\mathrm{mGlu}_{5}$ allosteric modulators can bind to overlapping but not identical sites, which could complicate interpretation of in vivo occupancy data, even when PET ligands and drug leads are developed from the same chemical scaffold. We now report that systemic administration of the novel mGlu 5 positive allosteric modulator VU0092273 displaced the structurally related mGlu ${ }_{5}$ PET ligand, $\left[{ }^{18} \mathrm{~F}\right] \mathrm{FPEB}$, with measures of in vivo occupancy that closely aligned with its in vivo efficacy. In contrast, a close analog of VU0092273 and [ $\left.{ }^{18} \mathrm{~F}\right] \mathrm{FPEB}, \mathrm{VU0360172}$, provided robust efficacy in rodent models in the absence of detectable occupancy. Furthermore, a structurally unrelated mGlu negative allosteric modulator, VU0409 I06, displayed measures of in vivo occupancy that correlated well with behavioral effects, despite the fact that VU0409/06 is structurally unrelated to $\left[{ }^{18} \mathrm{~F} F \mathrm{FPEB}\right.$. Interestingly, all three compounds inhibit radioligand binding to the prototypical MPEP/FPEB allosteric site in vitro. However, VU0092273 and VU0409I06 bind to this site in a fully competitive manner, whereas the interaction of VU0360I72 is noncompetitive. Thus, while close structural similarity between PET ligands and drug leads does not circumvent issues associated with differential binding to a given target, detailed molecular pharmacology analysis accurately predicts utility of ligand pairs for in vivo occupancy studies.

Neuropsychopharmacology (20I5) 40, 755-765; doi:I0.I038/npp.20I4.245; published online 22 October 2014
\end{abstract}

\section{INTRODUCTION}

The metabotropic glutamate receptor subtype $5\left(\mathrm{mGlu}_{5}\right)$ has emerged as an exciting new target for treatment of multiple neurological and psychiatric disorders. Selective $\mathrm{mGlu}_{5}$ negative allosteric modulators (NAMs) are advancing in clinical development for treatment of Fragile X syndrome, Parkinson's disease, and affective disorders (Berg et al, 2011; Emmitte, 2013; Jacquemont et al, 2011) and positive allosteric modulators (PAMs) of $\mathrm{mGlu}_{5}$ may provide a novel approach to treatment of psychosis and cognitive

*Correspondence: Dr PJ Conn, Department of Pharmacology and Vanderbilt Center for Neuroscience Drug Discovery, Vanderbilt University Medical Center, 1215D Light Hall, 22 I5-B Garland Avenue, Nashville, TN 37232-0697, USA, Tel: + I 615936 2478, Fax: + I 615343 3088, E-mail: jeff.conn@vanderbilt.edu

Received I4 May 2014; revised 6 September 2014; accepted 9 September 2014; accepted article preview online 22 September 2014 disturbances in schizophrenia patients (Conn et al, 2011; Noetzel et al, 2012).

Advancing $\mathrm{mGlu}_{5}$ allosteric modulators in early clinical studies has been facilitated by the availability of highly selective positron emission tomography (PET) radioligands that allow unambiguous quantitative assessment of receptor occupancy (RO) in the brain after systemic administration of defined doses of test compounds (Majo et al, 2013; $\mathrm{Mu}$ et al, 2010). Determining the level of RO necessary for efficacy and adverse effects provides a noninvasive translational biomarker ideal for assessing the dose range required to engage the targeted receptor in preclinical and clinical studies (Bergstrom et al, 2004). The majority of drug candidates that enter development for central nervous system (CNS) disorders fail in late stage development owing to an inability to establish efficacy (Raskin and Casdin, 2011). Late stage failure is most commonly observed when adequate biomarker strategies are not available to allow definitive dose-finding studies (Kola, 2008). In instances where target engagement is not assessed, failure to achieve 
efficacy may be because of inadequate CNS exposure rather than lack of potential efficacy of the mechanism. Thus, it is critical to take full advantage of available radioligands for advancing novel $\mathrm{mGlu}_{5}$ allosteric modulators into clinical development.

The highly selective $\mathrm{mGlu}_{5}$ allosteric radioligand $\left[{ }^{18} \mathrm{~F}\right] \mathrm{FPEB}$ (Hamill et al, 2005) binds to an allosteric site on $\mathrm{mGlu}_{5}$ that is occupied by the prototypical mGlu $\mathrm{NAM}$, 2-methyl-6-(phenylethynyl)pyridine hydrochloride (MPEP), and is being used to assess $\mathrm{mGlu}_{5}$ occupancy in multiple clinical studies (Hamill et al, 2005; Russell, 2014; Wang et al, 2007; Wong et al, 2013). It is clear that allosteric modulators can bind to multiple topographically distinct allosteric sites on $\mathrm{mGlu}_{5}$ (Gregory et al, 2014; Gregory et al, 2013). Therefore, many investigators rely on parallel optimization of PET ligands and drug leads from the same chemical scaffold to avoid complications associated with use of PET ligands and drug leads that do not interact with identical sites. However, recent molecular pharmacology, structural and molecular modeling studies provide the surprising finding that closely related $\mathrm{mGlu}_{5}$ allosteric modulators based on a single scaffold can inhibit binding of ligands to the prototypical MPEP $/\left[{ }^{18} \mathrm{~F}\right] \mathrm{FPEB}$ site by docking to overlapping but nonidentical sites within a large allosteric binding pocket (Chen et al, 2007; Dore et al, 2014; Gregory et al, 2014; Gregory et al, 2013; Rodriguez et al, 2010; Rodriguez et al, 2005; Wu et al, 2014). Conversely, molecular pharmacology and docking studies suggest that structurally unrelated mGlu receptor modulators can bind to the identical binding site in a fully competitive manner (Gregory et al, 2014; Gregory et al, 2013). These studies raise the possibility that very closely related $\mathrm{mGlu}_{5}$ modulators based on a single chemical scaffold may interact in a noncompetitive manner, which could complicate interpretation of in vivo occupancy studies. We now report that two highly selective GGlu $_{5}$ PAMs (VU0092273 and VU0360172), both of which are close analogs within the same biaryl acetylenic nicotinamide chemical series as FPEB and MPEP (Noetzel et al, 2012; Rodriguez et al, 2010), show fundamentally different profiles in when assessing in vivo occupancy using $\left[{ }^{18} \mathrm{~F}\right] \mathrm{FPEB}$. Systemic administration of VU0092273 displaced $\left[{ }^{18} \mathrm{~F}\right] \mathrm{FPEB}$, with occupancies that closely align with its in vivo efficacy, whereas VU0360172 does not displace $\left[{ }^{18} \mathrm{~F}\right] \mathrm{FPEB}$ at doses well above those required for antipsychotic-like activity. In addition, a novel mGlu $_{5}$ NAM, VU0409106, that bears no structural similarity to FPEB and MPEP, displaced $\left[{ }^{18} \mathrm{~F}\right] \mathrm{FPEB}$ binding in vivo, and displayed in vivo occupancy that fits well with its in vivo efficacy. Interestingly, all three allosteric modulators inhibit binding of a radioligand to the MPEP site in vitro. However, VU0092273 and VU0409106 interact with this site in a fully competitive manner, whereas VU0360172 interacts with this site in a manner that is not fully competitive. Thus, recent structural and modeling studies revealing that minor structural changes within the same chemical scaffold can significantly alter the binding interaction of mGlu receptor allosteric modulators has direct relevance to interpretation of results from in vivo occupancy studies. However, rigorous molecular pharmacology evaluation of binding interactions between individual systemically administered allosteric modulators and specific radioligands accurately predicts utility of ligand pairs for in vivo occupancy studies.

\section{MATERIALS AND METHODS}

\section{Materials}

Dulbecco's modified Eagle's medium, fetal bovine serum and antibiotics were purchased from Invitrogen (Carlsbad, CA). $\left[{ }^{3} \mathrm{H}\right]$-labeled 3-methoxy-5-pyridin-2-pyridinylethynyl) pyridine $\left(\left[{ }^{3} \mathrm{H}\right] \mathrm{mPEPy}\right)$ was purchased from PerkinElmer (Waltham, MA). MPEP was purchased from Tocris Bioscience (Elllisville, MO). VU0092273 (Rodriguez et al, 2010), VU0360172 (Rodriguez et al, 2010), VU0240382 (Williams et al, 2011), 5-methyl-2-phenylethynyl-pyridine (5MPEP) (Rodriguez et al, 2005), 3-((2-Methyl-4-thiazolyl) ethynyl)pyridine (MTEP) (Cosford et al, 2003b), and $\left[{ }^{18} \mathrm{~F}\right] \mathrm{FPEB}$ (Ansari et al, 2010; Hamill et al, 2005; Patel et al, 2005) were synthesized as described previously. Unless otherwise stated, all other reagents were purchased from Sigma-Aldrich (St Louis, MO) and were either analytical or HPLC grade.

\section{Animals}

All animal experiments were conducted in accordance with the National Institutes of Health Guide for the Care and Use of Laboratory Animals and were approved by the Institutional Animal Care and Use Committee. Male SpragueDawley rats (Harlan, Indianapolis, IN) weighing 275-325 g were housed three per cage under a 12-h light/dark cycle with access to food and water ad libitum.

\section{Micro PET Imaging}

Rats underwent surgery for carotid and jugular catheter insertion. Approximately 5 days later, rats were given an intraperitoneal (i.p.) injection of vehicle (10\% Tween 80$)$ or test compound in a $3-\mathrm{ml} / \mathrm{kg}$ volume. Thirty minutes post injection, rats were anesthetized using $1.5 \%$ isofluorane and positioned in a micro PET Focus 220 (Siemens, Knoxville, TN). Approximately $\sim 15 \mathrm{MBq} / 0.24 \mathrm{ml}\left[{ }^{18} \mathrm{~F}\right] \mathrm{FPEB}$ were injected via jugular catheter while simultaneously starting a 60-min dynamic acquisition. Blood samples were drawn via arterial catheter every $15 \mathrm{~s}$ for the first $2 \mathrm{~min}$, then at $4,6,8,12,20,30,45$, and $60 \mathrm{~min}$. Samples were centrifuged and plasma activity was measured using a well counter (Capintec, Ramsey, NJ). Through acetonitrile extraction and thin layer chromatography, metabolite corrections were carried out on selected blood samples (2, 12, 30 and $60 \mathrm{~min}$ ) and a metabolite-corrected arterial plasma input function was constructed. Attenuation corrections were carried out using a ${ }^{57} \mathrm{Co}$ transmission scan. Images were reconstructed using OSEM 2D. The dynamic PET images consisted of five $60 \mathrm{~s}$ frames, two $150 \mathrm{~s}$ frames, two $300 \mathrm{~s}$ frames, and three $600 \mathrm{~s}$ frames. The data from all possible lines of response were saved in list mode and reconstructed using OSEM 2D with 16 subsets and 4 iterations after applying scatter and attenuation corrections. The reconstructed image matrix consisted of $128 \times 128 \times 95$ voxels with voxel sizes of $0.095 \times 0.095 \times 0.08 \mathrm{~cm}^{3}$. The PET images were manually co-registered to an MRI rat brain template (Rubins et al, 2003) using Amide software (Loening and Gambhir, 2003). Regions-of-interest were drawn around the cerebellum and striatum of the template and superimposed on the PET images. Time-activity curves were established for these 
regions over the entire duration of the scan. Total volume of distribution $\left(V_{\mathrm{T}}\right)$ using graphical analysis (Logan, 2000; Logan et al, 1996) was estimated for the striatum and cerebellum using PMOD (PMOD Technologies, Zurich, Switzerland). Percent occupancy was calculated as: percent occupancy $=\left(\left(V_{\text {Tvehicle }}-V_{\text {Ttreatment }}\right) / V_{\text {Tvehicle }}\right) \times 100$. Data were expressed as mean \pm SEM Data were normalized using the maximum occupancy of $3 \mathrm{mg} / \mathrm{kg}$ MTEP and analyzed using GraphPad Prism 5.0 (GraphPad Software, San Diego, CA).

\section{Amphetamine-Induced Hyperlocomotion}

Testing procedures were performed as previously described (Noetzel et al, 2012). In brief, test compounds were dissolved in 10\% Tween 80 and double-deionized water, and the $\mathrm{pH}$ was adjusted to $\sim 7.0$ using $1 \mathrm{~N} \mathrm{NaOH}$. Test compounds were administered i.p. in a $3-\mathrm{ml} / \mathrm{kg}$ volume. Vehicle or test compound was administered following a 30-min habituation period to an open-field chamber (KinderScientific, San Diego, CA). After an additional $30 \mathrm{~min}$, rats received a saline vehicle or $1 \mathrm{mg} / \mathrm{kg}$ amphetamine injection subcutaneously. Locomotor activity was measured for an additional $60 \mathrm{~min}$ and depicted as the number of total photobeam breaks per 5-min intervals using Motor Monitor System software (KinderScientific). Main effects of test compound treatment on the locomotor activity area under the time course curve were evaluated using one-way analysis of variance. Comparisons of treatment group effects relative to the vehicle + amphetamine group were completed across the time interval from $t=60$ -120 min using Dunnett's post hoc tests with a $p$ value of $<0.05$ considered significant.

\section{Elevated Plus Maze}

On the test day, rats were pretreated with vehicle or a dose of VU0409106 (1, 3, 10, or $30 \mathrm{mg} / \mathrm{kg}$ i.p.) and then acclimated in the testing room for $1 \mathrm{~h}$. A 5 -min test session began by placing each rat on the central platform facing an open arm of the elevated plus maze. Data were manually scored by an observer blinded to dose and expressed as time spent in the open arms as a percentage of the total testing time. Data were expressed as mean $\pm \operatorname{SEM}(n=8)$. Main effects of test compound treatment on the percent time spent in open arms of the maze were evaluated using oneway analysis of variance. Comparisons of treatment group effects relative to the vehicle group were completed using Dunnett's post hoc tests with a $p$ value of $<0.05$ considered significant.

\section{Radioligand Binding Assays}

The interaction of novel $\mathrm{mGlu}_{5}$ PAMs with the allosteric antagonist MPEP analog $\left[{ }^{3} \mathrm{H}\right] \mathrm{mPEPy}$ (Cosford et al, 2003a) was assessed using membranes preparations from HEK293A cells stably expressing rat $\mathrm{mGlu}_{5}$ as previously described (Rook et al, 2012). In brief, compound concentrationresponse curves were diluted into assay buffer and added to each well of a 96-well plate, along with $50 \mu \mathrm{g} /$ well cell membrane and $5 \mathrm{nM}\left[{ }^{3} \mathrm{H}\right] \mathrm{mPEPy}$. Following a 60 -min incubation period at room temperature, the membrane-bound ligand was separated from free ligand by filtration through glass fiber 96-well filter plates (Unifilter-96, GF/B; Perkin Elmer Life and Analytical Sciences, Boston, MA). Forty microliters of scintillation fluid was added to each well, and the membrane-bound radioactivity was determined by scintillation counting (TopCount; PerkinElmer Life and Analytical Sciences). Nonspecific binding was estimated using $10 \mu \mathrm{M}$ MPEP.

\section{Fluorescence-Based Calcium Assays in Rat $\mathbf{m G l u}_{5}$ Cells}

HEK293A cells lines stably expressing rat $\mathrm{mGlu}_{5}$ or polyclonal mutant rat $\mathrm{mGlu}_{5}$ derived from the wild-type rat $\mathrm{mGlu}_{5}$ gene were maintained and site-directed point mutations in rat $\mathrm{mGlu}_{5}$-pCl:Neo (A809V and F585I) were generated as previously described (Gregory et al, 2012; Noetzel et al, 2012; Rook et al, 2012). Quantification of $\mathrm{mGlu}_{5}$-mediated intracellular $\mathrm{Ca}^{2}+$ mobilization was performed using Fluo- $4, \mathrm{a} \mathrm{Ca}^{2+}$ sensitive dye, and a Flexstation II (Noetzel et al, 2012; Rodriguez et al, 2010; Rook et al, 2012). For 5-methyl-6-(phenylethynyl)-pyridine (5MPEP) assays, a 210-s protocol was used. 5MPEP was added at $20 \mathrm{~s}$, followed by a PAM concentration-response curve at $80 \mathrm{~s}$. An $\mathrm{EC}_{20}$ of glutamate was added at $170 \mathrm{~s}$. Fold shift data was determined using a 130-s protocol where calcium assay buffer or $10 \mu \mathrm{M}$ PAM was added at $20 \mathrm{~s}$ followed by a glutamate concentration-response curve at $90 \mathrm{~s}$. Peak fluorescence response was obtained following the last compound addition and normalized to maximum glutamate response for each assay. Data were analyzed using GraphPad Prism 5.0 (GraphPad Software, San Diego, CA).

\section{RESULTS}

\section{In Vivo RO/Efficacy Relationship of $\mathrm{mGlu}_{5}$ PAMs}

Based on the previous findings that Glu $_{5}$ PAMs display antipsychotic-like activity and cognition enhancement in preclinical models, we sought to test the hypothesis that there will be a close relationship between $\mathrm{mGlu}_{5}$ in vivo $\mathrm{RO}$ in the CNS and efficacy of $\mathrm{mGlu}_{5}$ PAMs in reversing amphetamine-induced hyperlocomotion (AHL), a common preclinical assay utilized to assess antipsychotic-like activity of novel compounds. VU0092273 and VU0360172 are highly selective $\mathrm{mGlu}_{5}$ PAMs that possess robust efficacy in reversing AHL (Noetzel et al, 2012) and provide excellent tools to assess the $\mathrm{mGlu}_{5} \mathrm{RO} /$ efficacy relationship of $\mathrm{mGlu}_{5}$ PAMs. Also, VU0092273 and VU0360172 are close structural analogs based on the same biaryl acetylenic nicotinamide scaffold as $\left[{ }^{18} \mathrm{~F}\right] \mathrm{FPEB}, \mathrm{MPEP}$, and MTEP (Figure 1). Finally, VU0092273 and VU0360172 potentiate responses to $\mathrm{EC}_{20}$ concentrations of glutamate in cells expressing $\mathrm{mGlu}_{5}$ with similar $\mathrm{EC}_{50}$ values of $35 \pm 5$ and $13 \pm 2 \mathrm{nM}$ (mean $\pm \mathrm{SEM}$ ), respectively (Noetzel et al, 2012; Rodriguez et al, 2010). Thus, we performed PET imaging studies to determine whether $\left[{ }^{18} \mathrm{~F}\right] \mathrm{FPEB}$ is appropriate for evaluation of the in vivo RO of these two closely related $\mathrm{mGlu}_{5}$ PAMs. For comparison, we also evaluated the effect of MTEP as a prototypical biaryl acetylenic $\mathrm{mGlu}_{5}$ NAM ligand at this site.

Figure $2 \mathrm{a}$ depicts representative images of $\left[{ }^{18} \mathrm{~F}\right] \mathrm{FPEB}$ binding in rat brains following pretreatment with either 

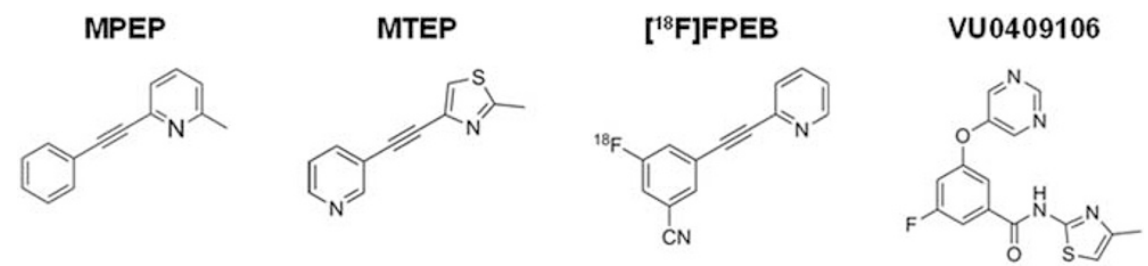

VU0092273

\section{VU0360172}
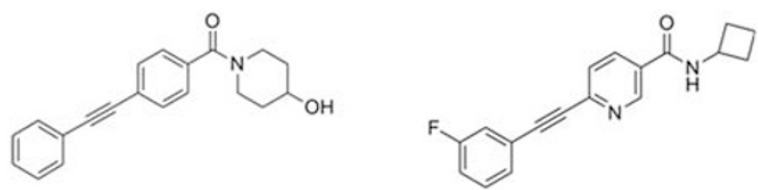

Figure I Structure activity relationship and binding interaction of mGlus (metabotropic glutamate receptor subtype 5) positive allosteric modulators (PAMs). VU0092273 and VU0360I72 are mGlu PAMs and closely related structural analogs of the prototypical mGlu negative allosteric modulator (NAM), MPEP (methyl-6-(phenylethynyl)pyridine hydrochloride), and the mGlu 5 NAM PET ligand [ ${ }^{18}$ F]FPEB. VU0409I 06 is structurally distinct from both mGlu 5 PAM and NAMs.

VU0092273, VU0360172, or MTEP. Consistent with previous studies (Anderson et al, 2003; Wang et al, 2007), MTEP (3 mg/kg, i.p.) induced a reduction of $\left[{ }^{18} \mathrm{~F}\right] \mathrm{FPEB}$ binding in the striatum of rats assessed $30 \mathrm{~min}$ after administration, with a maximal occupancy of $89 \%$. Initial studies with MTEP demonstrated a 20\% reduction in binding within the cerebellum, confirming significant $\mathrm{mGlu}_{5}$ expression within this brain region (data not shown). Therefore, arterial plasma input function and graphical analysis was utilized for PET imaging data analysis as opposed to a reference tissue model. Increasing doses of VU0092273 (3-100 mg/kg, i.p.) induced a similar reduction of $\left[{ }^{18} \mathrm{~F}\right] \mathrm{FPEB}$ binding in the striatum with an $\mathrm{ED}_{50}$ value of $17.3 \mathrm{mg} / \mathrm{kg}$ and maximal occupancy of $80.8 \%$ following $100 \mathrm{mg} / \mathrm{kg}$ administration i.p. (Figure 2a and b). Surprisingly, the closely related $\mathrm{mGlu}_{5}$ PAM, VU0360172, did not significantly reduce $\left[{ }^{18} \mathrm{~F}\right] \mathrm{FPEB}$ binding in striatum in vivo at doses up to $100 \mathrm{mg} / \mathrm{kg}$ (Figure $2 \mathrm{a}$ and $\mathrm{c}$ ).

To relate the in vivo occupancy studies to a common measure of efficacy of $\mathrm{mGlu}_{5}$ PAMs, the effect of increasing doses of VU0092273 and VU0360172 (10-56.6 mg/kg, i.p.) on AHL was evaluated. Both $\mathrm{mGlu}_{5}$ PAMs induced dosedependent reversal of increases in locomotor activity caused by administration of $1 \mathrm{mg} / \mathrm{kg}$ amphetamine (subcutaneously, $p<0.0001$ ). The $\mathrm{ED}_{50}$ value of VU0092273 was $11.6 \mathrm{mg} / \mathrm{kg}$ with a maximum reversal of $67.3 \%$ (Figure $3 \mathrm{a}$ ), demonstrating robust antipsychotic-like efficacy. VU0360172 demonstrated similar dose-dependent in vivo efficacy in this assay with an $\mathrm{ED}_{50}$ value of $15.2 \mathrm{mg} / \mathrm{kg}$ and maximum reversal of $60.7 \%$ (Figure $3 \mathrm{~b}$ ). Importantly, the in vivo potencies and maximal efficacies of these two $\mathrm{mGlu}_{5}$ PAMs were similar. The potency of VU0092273 in occupying the allosteric site on $\mathrm{mGlu}_{5}$ labeled by $\left[{ }^{18} \mathrm{~F}\right] \mathrm{FPEB}\left(\mathrm{ED}_{50}=17.3\right.$ $\mathrm{mg} / \mathrm{kg}$; Figure $2 \mathrm{~b}$ ) is in close agreement with the potency of this $\mathrm{mGlu}_{5}$ PAM in reversing AHL $\left(\mathrm{ED}_{50}=11.6 \mathrm{mg} / \mathrm{kg}\right)$. Furthermore, the in vivo RO achieved with the minimal effective dose $(10 \mathrm{mg} / \mathrm{kg})$ of VU0092273 in AHL was $26 \%$. The occupancy achieved with the lowest dose required for full efficacy $(30 \mathrm{mg} / \mathrm{kg}$ ) was $\sim 60 \%$. These data reveal a close occupancy/efficacy relationship for this compound with relatively low RO required to achieve in vivo efficacy. In addition, full occupancy is not necessary to obtain maximal efficacy in this behavioral assay. However, the lack of effect of VU0360172 on $\left[{ }^{18} \mathrm{~F}\right] \mathrm{FPEB}$ binding suggests a more complex relationship between in vivo $\left[{ }^{18} \mathrm{~F}\right] \mathrm{FPEB}$ site binding and efficacy for these two closely related $\mathrm{mGlu}_{5}$ NAMs. Importantly, the $\mathrm{mGlu}_{5}$ antagonist, MPEP, blocked in vivo efficacy of the PAM in reversing AHL, supporting an $\mathrm{mGlu}_{5^{-}}$ mediated effect (data not shown).

As a negative control, we also performed studies with VU0240382, a close structural analog of VU0092273, that is a potent $\mathrm{mGlu}_{5}$ PAM that has been shown to interact with the MPEP/FPEB site in a fully competitive manner (Noetzel et al, 2012; Rook et al, 2011). However, VU0240382 does not achieve appreciable brain exposure. We previously reported that the unbound fraction of VU0240382 in rat brain after systemic administration is $0.01 \%$, resulting in low brain exposure after systemic administration (Noetzel et al, 2012). Consistent with this, a relatively high dose of VU0240382 $(56.6 \mathrm{mg} / \mathrm{kg}$, i.p.), did not significantly reverse AHL (Figure 4a). In contrast to MTEP and VU0092273, VU0240382 did not significantly displace $\left[{ }^{18} \mathrm{~F}\right] \mathrm{FPEB}$ binding in vivo (Figure $4 \mathrm{~b}$ ). This is consistent with the low brain exposure and lack of in vivo efficacy in the AHL model achieved with systemic administration of this compound.

In addition to evaluating the in vivo efficacy/occupancy relationship of closely related members of the biaryl acetylenic $\mathrm{mGlu}_{5}$ allosteric modulator series, we also evaluated

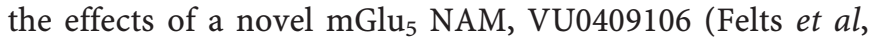
2013). This $\mathrm{mGlu}_{5} \mathrm{NAM}$ bears no structural resemblance to FPEB and the other $\mathrm{mGlu}_{5}$ modulators studied (Figure 1). However, recent molecular modeling and docking studies suggest that this $\mathrm{mGlu}_{5} \mathrm{NAM}$ binds to the MPEP/FPEB site in a manner similar to MPEP (Gregory et al, 2013). Interestingly, VU0409106 induced a dose-dependent displacement of in vivo $\left[{ }^{18} \mathrm{~F}\right] \mathrm{FPEB}$ binding with an $\mathrm{ED}_{50}$ of $7.5 \mathrm{mg} / \mathrm{kg}$ and maximum occupancy of $87.7 \%$ at $30 \mathrm{mg} / \mathrm{kg}$ (Figure $4 \mathrm{c}$ and d). Consistent with the established anxiolytic-like activity of $\mathrm{mGlu}_{5}$ NAMs, VU0409106 dosedependently enhanced the percent time spent in the open arms of the elevated plus maze $(p<0.0001)$ with an $\mathrm{ED}_{50}$ of $8.2 \mathrm{mg} / \mathrm{kg}$ and a maximum increase of $29.2 \%$ (Figure $4 \mathrm{~d}$ ). 
a

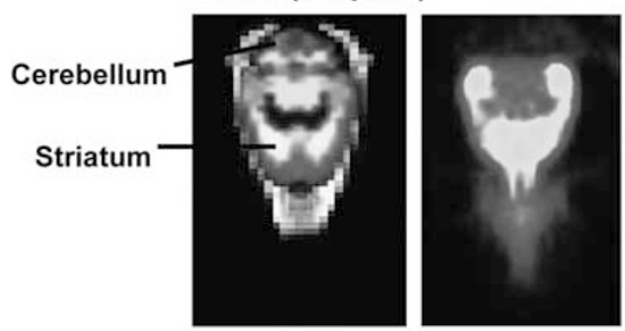

Vehicle

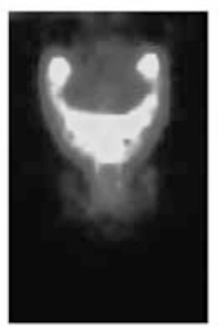

$10 \mathrm{mg} / \mathrm{kg}$
PET (experimental)
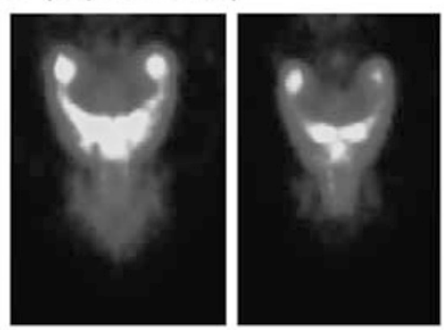

$30 \mathrm{mg} / \mathrm{kg}$
$100 \mathrm{mg} / \mathrm{kg}$

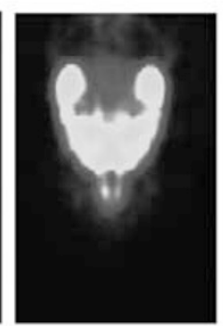

$100 \mathrm{mg} / \mathrm{kg}$

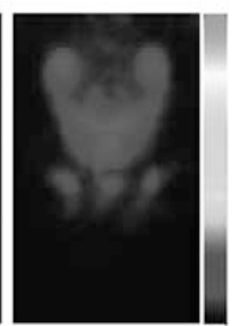

$3 \mathrm{mg} / \mathrm{kg}$

VU0360172 MTEP

b
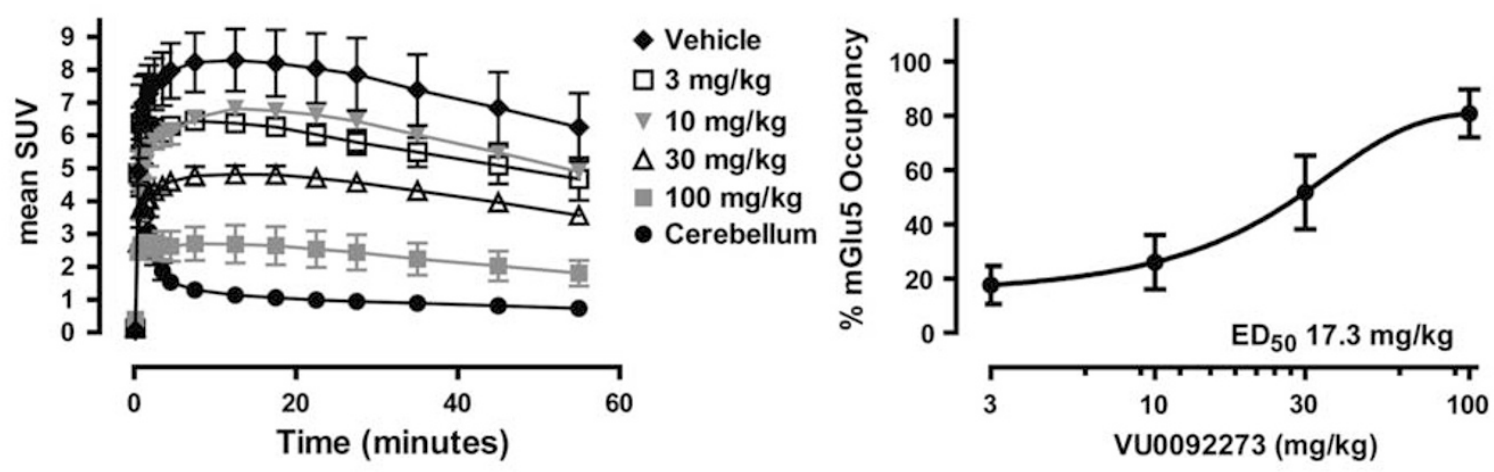

c

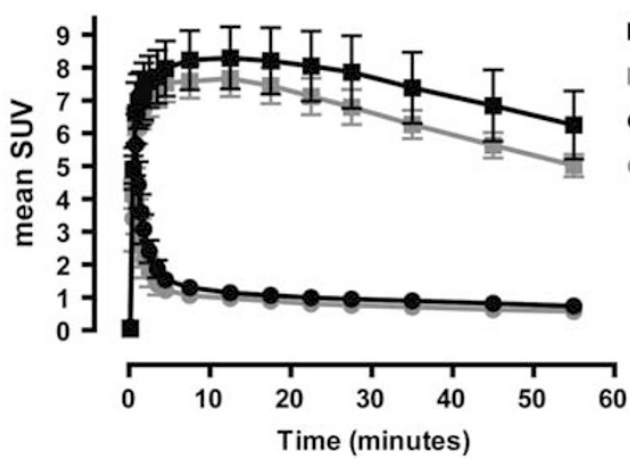

- Striatum Vehicle

- Striatum VU0360172

- Cerebellum Vehicle

- Cerebellum VU0360172

Figure 2 VU0092273 displays dose-dependent in vivo receptor occupancy (RO) of the mGlu (metabotropic glutamate receptor subtype 5) MPEP (methyl-6-(phenylethynyl)pyridine hydrochloride) site. (a) Positron emission tomography representative images of $\left.{ }^{18} \mathrm{~F}\right] \mathrm{FPEB}$ binding in vehicle-, VU0092273-, VU0360172-, and MTEP-treated rat brains. (b) Pretreatment with VU0092273 (3-100 mg/kg, i.p.) dose-dependently displaces [ ${ }^{18} \mathrm{~F}$ FPEB binding in the striatum with an $\mathrm{ED}_{50}$ of $17.3 \mathrm{mg} / \mathrm{kg}$ and maximum percent occupancy of $80.1 \pm 8$. (c) In addition, VU0360 I72 does not significantly displace $\left[{ }^{18} \mathrm{~F}\right] \mathrm{FPEB}$ binding to $\mathrm{mGlu}_{5}$ in vivo, demonstrating that $\mathrm{RO}$ does not predict in vivo efficacy for this $\mathrm{mGlu} \mathrm{u}_{5} \mathrm{PAM}$. Time-activity curve of $\left[{ }^{18} \mathrm{~F}\right] \mathrm{FPEB}$ binding in the cerebellum and striatum following vehicle and VU0360I72 (I $00 \mathrm{mg} / \mathrm{kg}, 30 \mathrm{~min}$, i.p.). Data represent mean standard uptake value \pm SEM ( $n=5-7)$.

Thus, the potency of VU0409106 in occupying the MPEP site of $\mathrm{mGlu}_{5}$ aligns closely with its potency in the elevated plus maze assay $(8.2 \mathrm{mg} / \mathrm{kg})$. In addition, these data are in line with occupancies of other $\mathrm{mGlu}_{5}$ NAMs that are required for efficacy in the elevated plus maze assay.

Differential Interaction of $\mathrm{mGlu}_{5}$ PAMs with the Prototypical Allosteric MPEP Site

Based on the close structural similarities of VU0092273 and VU0360172 to MPEP and FPEB, we originally postulated that each of these compounds would interact with a previously defined allosteric site that is shared by multiple
mGlu $_{5}$ modulators, including MPEP and FPEB. However, the finding that VU0360172 does not reduce in vivo $\left[{ }^{18} \mathrm{~F}\right] \mathrm{FPEB}$ binding at doses that have full efficacy in rodent models suggests an added complexity to the nature of interactions between these ligands or the relationship between $\mathrm{mGlu}_{5}$ occupancy and efficacy. Interestingly, mutagenesis and structural docking studies suggest that VU0360172 may interact with the MPEP/FPEB site in a manner that is overlapping but not identical with the interaction by MPEP (Gregory et al, 2013). Thus, it is conceivable that the lack of effect of VU0360172 on in vivo $\left[{ }^{18} \mathrm{~F}\right] \mathrm{FPEB}$ binding reflects a more complex interaction at this site that has been predicted by structural modeling 


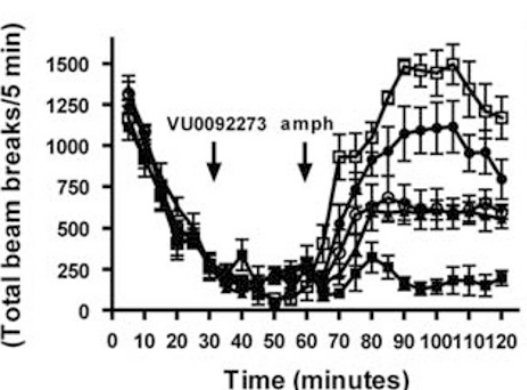

- vehicle + vehicle

$\square$ vehicle + amph

- $10 \mathrm{mg} / \mathrm{kg}+\mathrm{amph}$

○ $30 \mathrm{mg} / \mathrm{kg}+\mathrm{amph}$

$56.6 \mathrm{mg} / \mathrm{kg}+\mathrm{amph}$

Time (minutes)

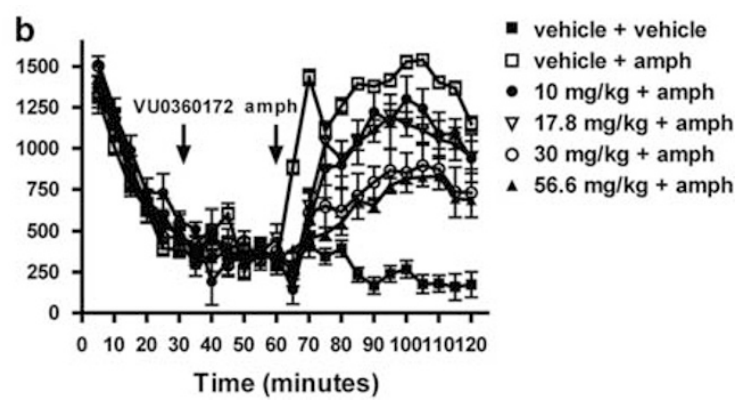

Figure 3 Despite differential displacement of $\left[{ }^{18} \mathrm{~F}\right] \mathrm{FPEB}$ in vivo, both VU0360I72 and VU0092273 exhibit an antipsychotic-like profile in rats. (a) VU0092273, an mGlus (metabotropic glutamate receptor subtype 5) positive allosteric modulator, displays antipsychotic-like activity. Male Sprague-Dawley rats treated with increasing doses of VU0092273 ( I 0-56.6 mg/ $/ \mathrm{kg}$, i.p.) exhibited dose-dependent reversal of amphetamine-induced hyperlocomotion with an $\mathrm{ED}_{50}$ of $11.6 \mathrm{mg} / \mathrm{kg}$ and maximum efficacy observed at a dose of $30 \mathrm{mg} / \mathrm{kg}$. Data represent mean $\pm \mathrm{SEM}(n=5-7)$. (b) VU0360/72 displayed antipsychotic-like activity similar to VU0092273. Male Sprague-Dawley rats treated with increasing doses of VU0360 I72 (I0-56.6 mg/kg, i.p.) exhibited dose-dependent reversal of amphetamine-induced hyperlocomotion with an $\mathrm{ED}_{50}$ of $15.2 \mathrm{mg} / \mathrm{kg}$. Data represent mean $\pm \mathrm{SEM}(n=5-8)$.

a

Amphetamine-induced Hyperlocomotion

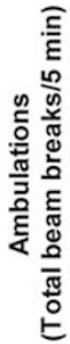

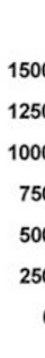

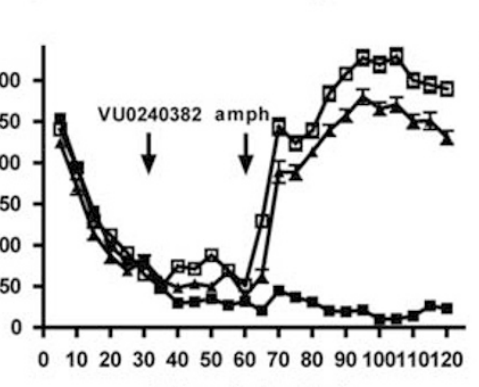

Time (minutes) b

- vehicle + vehicle

$\square$ vehicle + amph

A $56.6 \mathrm{mg} / \mathrm{kg}+\mathrm{amph}$

C

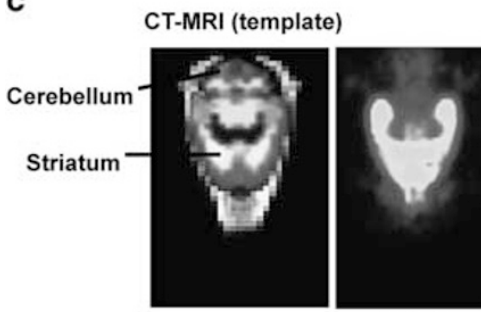

Vehicle

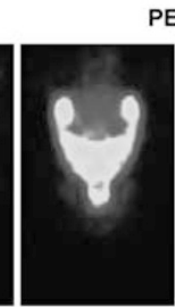

$1 \mathrm{mg} / \mathrm{kg}$

PET (experimental)
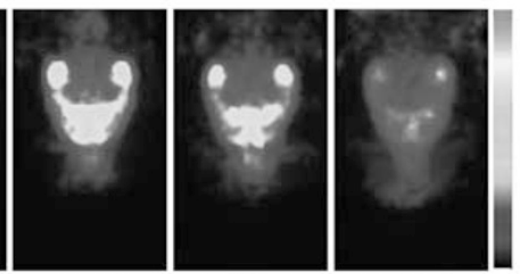

$10 \mathrm{mg} / \mathrm{kg} \quad 30 \mathrm{mg} / \mathrm{kg}$

VU0409106
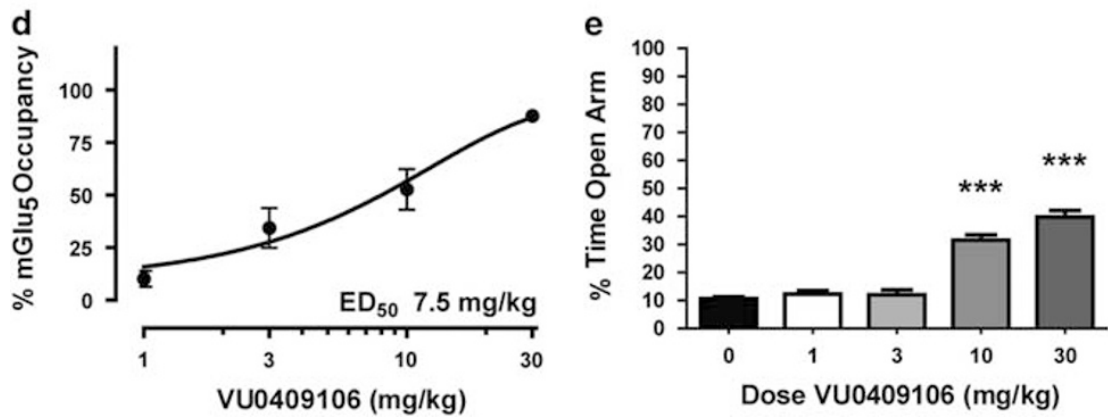

Figure 4 Subtle structural changes to $\mathrm{mGlu}_{5}$ (metabotropic glutamate receptor subtype 5) PAMs (positive allosteric modulators) result in significant alterations in in vivo efficacy and/or receptor occupancy. (a) Unlike VU0092273 and VU0360 I72, VU0240382 does not significantly reverse amphetamineinduced hyperlocomotion in rats $(56.6 \mathrm{mg} / \mathrm{kg}$, i.p.) Data represent mean \pm SEM ( $n=5-8)$. (b) The highly potent, selective mGlu 5 PAM, VU0240382, does not exhibit in vivo occupancy of mGlu 5 . VU0240382 does not significantly displace ${ }^{18} \mathrm{~F}$ FPEB binding in vivo. Time-activity curve of $\left.{ }^{18} \mathrm{~F}\right] \mathrm{FPEB}$ binding in the cerebellum and striatum following vehicle and VU0240382 (100 mg/kg, $30 \mathrm{~min}$, i.p.) administration. Data represent mean standard uptake value \pm SEM $(n=5-7)$. (c, d) Pretreatment with structurally diverse mGlu ${ }_{5}$ negative allosteric modulator, $V \cup 0409106$ (I-30 mg/kg, i.p.), dose-dependently displaces $\left[{ }^{18} \mathrm{~F}\right] \mathrm{FPEB}$ binding in the striatum with an $\mathrm{ED}_{50}$ of $7.5 \mathrm{mg} / \mathrm{kg}$ and maximum percent occupancy of $87.7 \% \pm 2$. Data represent mean $\pm \mathrm{SEM}$ ( $n=5-7$ ). (e) VU0409 I 06 demonstrated anxiolytic-like behavior in the elevated plus maze in male Sprague-Dawley rats. VU0409 I 06 dose-dependently (I-30 mg/kg i.p.) increased time spent in open arms with an $\mathrm{ED}_{50}$ of $8.2 \mathrm{mg} / \mathrm{kg}$. Data represent mean \pm SEM. $* * * * p<0.000 \mathrm{I}(n=8)$. 
studies. To further understand the nature of interactions of these ligands with the MPEP site, we performed equilibrium radioligand binding studies in membranes from cells expressing $\mathrm{mGlu}_{5}$ using $\left[{ }^{3} \mathrm{H}\right]$ methoxy-PEPy as a wellcharacterized radioligand for this site (Cosford et al, 2003a). VU0092273, VU0360172, VU0409106, FPEB, and MPEP all inhibited $\left[{ }^{3} \mathrm{H}\right]$ methoxy-PEPy binding to $\mathrm{mGlu}_{5^{-}}$ expressing cell membranes with rank order potencies of FPEB $(0.2 \mathrm{nM})>\operatorname{MPEP}(51 \mathrm{nM})>$ VU0409106 (118 nM) $>$ VU0360172 $(203 \mathrm{nM})>$ VU0092273 $(2.7 \mu \mathrm{M})$ (Figure 5a). This is in line with previous studies demonstrating that $\mathrm{mGlu}_{5}$ PAMs typically have higher potencies in functional assays than apparent affinities at the allosteric site owing to the combined influence of affinity and cooperativity in determining PAM functional potencies (Conn et al, 2009; Conn et al, 2014). However, in contrast to each of the other $\mathrm{mGlu}_{5}$ modulators, which fully displaced binding,
VU0360172 only partially inhibited $\left[{ }^{3} \mathrm{H}\right]$ methoxy-PEPy binding with a maximum inhibition of $83 \%$ (Figure 5a). Although FPEB and MPEP are known to interact with the MPEP site in a fully competitive manner, this finding raised the possibility that VU0360172 may interact with this site in a manner that is distinct from that of the other $\mathrm{mGlu}_{5}$ allosteric modulators and is not fully competitive. In addition, increasing the concentration of the radioligand resulted in a concentration-dependent decrease in $\left[{ }^{3} \mathrm{H}\right]$ methoxy-PEPy binding by VU0360172 (data not shown), further supporting a noncompetitive interaction with the MPEP site.

Based on these radioligand binding data, we performed further functional studies to rigorously evaluate the nature of the interaction between VU0092273, VU0360172, and VU0409106 at the MPEP site. Multiple previous studies have taken advantage of the MPEP-site neutral allosteric ligand,
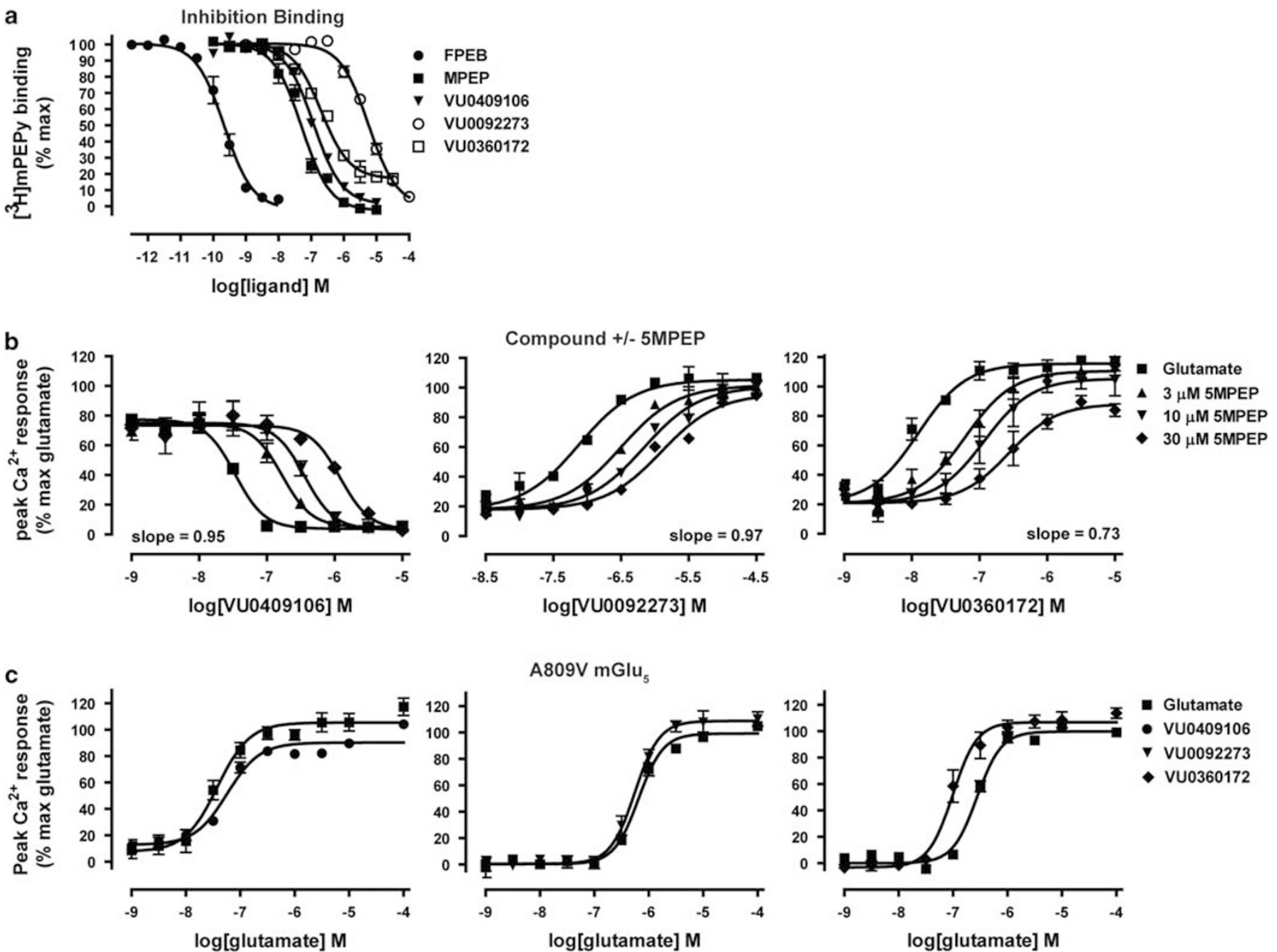

Figure 5 VU0092273 and VU0409I06 display differential interactions than VU0360 I 72 with the MPEP (methyl-6-(phenylethynyl)pyridine hydrochloride) binding site of $\mathrm{mGlu}_{5}$ (metabotropic glutamate receptor subtype 5). (a) VU0092273 and VU0409 I06, but not VU0360 I 72, fully inhibit [ ${ }^{3} \mathrm{H}$ ]methoxy-PEPy binding with potencies of $2.7 \mu \mathrm{M}$ and I I $8 \mathrm{nM}$ in mGlu 5 rat cell membranes. (b) Addition of increasing concentrations of the neutral ligand $5 \mathrm{MPEP}$ (5-methyl2-phenylethynyl-pyridine) results in a parallel rightward shift in VU0092273 and VU0409I06 concentration-response curve with no change in maximum glutamate response. However, 5MPEP decreases in the maximum glutamate response evoked by VU0360 I 72, and Schild regression analysis depicts a slope of 0.73 , suggesting a noncompetitive interaction. (c) Introduction of the single-point mutation A809V, which abolishes activity at the mGlu 5 allosteric MPEPsite, eliminated the shift in the glutamate concentration-response curves evoked by VU0092273 or VU0409 I 06 observed in polyclonal wild-type rat mGlu cells, while only partially attenuating the VU0360I72-induced fold shift (4.4 to 2.8). Data represent the mean \pm SEM of three independent experiments performed in duplicate. 
5MPEP, to perform Schild analyses to determine whether specific $\mathrm{mGlu}_{5}$ PAMs potentiate $\mathrm{mGlu}_{5}$-mediated responses by competitive interaction at the canonical MPEP site. Increasing concentrations of 5MPEP $(30-300 \mu \mathrm{M})$, induced concentration-dependent parallel rightward shifts of the VU0409106 or VU0092273 concentration-response curves at inhibiting or potentiating responses of glutamate, respectively, with no effect on the maximum glutamate response (Figure $5 \mathrm{~b}$ ). This is consistent with previous studies with other $\mathrm{mGlu}_{5}$ allosteric modulators (Chen et al, 2008; Chen et al, 2007; Rodriguez et al, 2010; Rodriguez et al, 2005; Rook et al, 2012) and supports the hypothesis that VU0092273 potentiates $\mathrm{mGlu}_{5}$-mediated responses by competitive interaction at the MPEP site. However, consistent with the radioligand binding studies, pretreatment of $\mathrm{mGlu}_{5}$-expressing cells with 5MPEP $(30-300 \mu \mathrm{M})$ significantly reduced the maximum response induced by VU0360172. Furthermore, Schild regression analysis of these data revealed a slope of unity for VU0409106 and VU0092273 but not VU0360172 (Figure 5b), suggesting that VU0409106 and VU0092273 elicit their effects by a competitive interaction with the MPEP allosteric binding site, whereas the interaction of VU0360172 with the MPEP site is noncompetitive in nature.

Additional studies utilized single-point mutagenesis of $\mathrm{mGlu}_{5}$ to further evaluate the interaction of VU0092273, VU0360172, and VU0409106 with the MPEP binding site. A single-point mutation $(\mathrm{A} 809 \mathrm{~V})$ was introduced into rat $\mathrm{mGlu}_{5}$, which has been previously shown to result in a loss of function of ligands that bind competitively to the MPEP site (Pagano et al, 2000; Rook et al, 2012). PAM activity of VU0092273 was completely abolished in cells expressing $\mathrm{mGlu}_{5}$-A809V. In addition, NAM activity of VU0409106 was also absent in $\mathrm{mGlu}_{5}-\mathrm{A} 809 \mathrm{~V}$ cells (Figure 5c). However, VU0360172-induced potentiation of the $\mathrm{mGlu}_{5}$-mediated response remained intact in the $\mathrm{A} 809 \mathrm{~V}$ mutant cells (Figure 5c). A similar effect with VU0360172 is observed in the S808A mGlu $\mathrm{m}_{5}$ mutation, which has also been shown to completely abolish MPEP site activity (data not shown) (Gregory et al, 2013). Taken together with the incomplete displacement of $\left[{ }^{3} \mathrm{H}\right]$ methoxy-PEPy binding and results from the Schild analysis, these data suggest that while structurally similar, VU0360172 does not interact with the MPEP site of $\mathrm{mGlu}_{5}$ in a fully competitive manner. Interestingly, while the mGlu ${ }_{5} \mathrm{NAM}$, VU0409106, is structurally distinct from MPEP, these data demonstrate a fully competitive interaction.

\section{DISCUSSION}

The use of PET imaging has emerged as a critical tool that allows quantitative assessment of interactions of novel pharmacological agents with their intended target in the CNS and other tissues to ensure accurate human dose projections (Bergstrom et al, 2004; Castner et al, 2014; Facklam et al, 1992). However, while direct measures of RO are viewed as more reliable than the use of functional biomarkers (EEG, fMRI, evoked potentials, and so on) for assessing target engagement, interactions of ligands with specific binding sites can be complex. A lack of understanding of the nature of these ligand-receptor interactions can complicate studies using selective ligands as imaging reagents to assess RO. Thus, it is critical to rigorously evaluate the interaction between each PET ligand and the drug lead or drug candidate being investigated.

Availability of $\left[{ }^{18} \mathrm{~F}\right] \mathrm{FPEB}$ and related ligands have played a critical role in guiding early clinical studies for $\mathrm{mGlu}_{5}$ NAMs and may also provide a viable approach for establishing CNS occupancy for $\mathrm{mGlu}_{5}$ PAMs. Two other $\mathrm{mGlu}_{5}$ radioligands that have been reported, $\left[{ }^{11} \mathrm{C}\right] \mathrm{ABP} 688$ (Ametamey et al, 2006) and $\left[{ }^{18} \mathrm{~F}\right]$ SP203 (Shetty et al, 2008), are structurally closely related to $\left[{ }^{18} \mathrm{~F}\right] \mathrm{FPEB}$ and developed from the MPEP scaffold (Andersson et al, 2013). As new allosteric modulators advance, it is hoped that developing drug candidates and PET ligands based on the same chemical scaffold will mitigate problems associated with complex interactions between different ligands acting at GPCR allosteric sites. Based on their close structural similarity, it is commonly assumed that these compounds bind to the same site as MPEP and FPEB in a fully competitive manner. However, recent advances in understanding the structural and molecular basis for allosteric modulator interactions with mGlu receptors reveal that closely related $\mathrm{mGlu}_{5}$ allosteric modulators can differentially interact with a single binding pocket. The present studies reveal that these in vitro complexities can lead to fundamentally different profiles when assessing in vivo occupancy with a closely related PET ligand. Thus, allosteric modulators that are close structural analogs of a given PET ligand may inhibit radioligand binding in vitro, but show fundamentally different profiles in reducing binding of a PET ligand in vivo. Thus, while $\left[{ }^{18} \mathrm{~F}\right] \mathrm{FPEB}$ provided an excellent measure of in vivo occupancy for VU0092273, this PET ligand was not useful for assessing occupancy of VU0360172. This is especially interesting in light of the finding that VU0360172 was actually more potent than VU0092273 in inhibiting equilibrium radioligand binding to this site in vitro using membrane preparations from cells expressing $\mathrm{mGlu}_{5}$. However, while both MPEP/FPEB analogs inhibit in vitro binding, detailed molecular pharmacological analysis reveals that VU0092273 does so in a fully competitive manner, whereas VU0360172 displays a noncompetitive interaction with this site. Furthermore, a structurally unrelated $\mathrm{mGlu}_{5} \mathrm{NAM}$, VU0409106, interacts with the FPEB/MPEP site in a fully competitive manner and displaces $\left[{ }^{18} \mathrm{~F}\right] \mathrm{FPEB}$ binding in vivo with a predicted occupancy that fits well with its in vivo efficacy. Thus, rigorous molecular pharmacological analysis was successful in accurately predicting utility of a given PET ligand for assessing occupancy of a test compound. These data are consistent with recent molecular modeling and docking studies that suggest that VU0360172 binds to the allosteric site on $\mathrm{mGlu}_{5}$ with a pose that is distinct from that of MPEP (Gregory et al, 2013). In contrast, docking studies predicted that VU0409106, while structurally distinct, binds to this site in a manner that is overlapping with the binding of MPEP or FPEB (Gregory et al, 2014). At present, it is not known whether $\left[{ }^{18} \mathrm{~F}\right] \mathrm{FPEB},\left[{ }^{11} \mathrm{C}\right] \mathrm{ABP} 688$, and $\left[{ }^{18} \mathrm{~F}\right] \mathrm{SP} 203$ bind to $\mathrm{mGlu}_{5}$ in the same manner, or whether they will assess different binding poses of allosteric modulators to this site. More recently, $\left[{ }^{11} \mathrm{C}\right]$ AZD9272 was reported as the first $\mathrm{mGlu}_{5}$ PET radioligand developed from a scaffold that is chemically distinct (Andersson et al, 2013). In future 
studies, it will be important to develop a full understanding of the nature of each of these radioligands with $\mathrm{mGlu}_{5}$.

Although VU0360172 interaction with the FPEB/MPEP site is not strictly competitive, it is still somewhat surprising that this compound inhibits binding to this site in vitro with a higher potency than VU0092273 but does not inhibit binding in vivo. VU0360172 achieved high brain concentrations (Noetzel et al, 2012) and had robust in vivo efficacy in reversal of AHL with an in vivo potency similar to that of VU0092273. This suggests that this mGlu $_{5}$ PAM clearly enters the brain at concentrations sufficient to potentiate $\mathrm{mGlu}_{5}$ and illustrates the critical issue of context dependence of complex noncompetitive ligand interactions that can impact in vivo studies. In cases where two ligands interact with a site in a noncompetitive manner, the interactions between the two ligands can vary widely depending on the specific cellular and membrane environment in different cell populations. The finding that VU0360172 was unable to displace $\left[{ }^{18} \mathrm{~F}\right] \mathrm{FPEB}$ binding in vivo provides a clear demonstration of the critical impact of subtle variation of the nature of interactions of individual drug leads with specific PET ligands and the need to rigorously evaluate the nature of this interaction for each ligand pair before advancing to in vivo RO studies.

For test compounds whose occupancy could be accurately assessed using $\left[{ }^{18} \mathrm{~F}\right] \mathrm{FPEB}$, these studies also provide new insights into the $\mathrm{RO} /$ efficacy relationship. Maximum in vivo efficacy of the mGlu ${ }_{5}$ PAM VU0092273 in the AHL model is observed at relatively low RO. Unlike NAMs, which demonstrate a close correlation between potency and affinity at $\mathrm{mGlu}_{5}, \mathrm{mGlu}_{5}$ PAMs have been shown to possess significant positive cooperativity between the functional potency in potentiating the glutamate response at $\mathrm{mGlu}_{5}$ and their affinity for the receptor (Chen et al, 2007; Conn et al, 2014; Gregory et al, 2012). Although this phenomenon has been extensively evaluated in in vitro systems, it remained unknown as to whether this was an artifact of the artificial systems used. These data provide the first direct evidence that the relationship of positive cooperativity exists in vivo. Therefore, these data suggest that when designing a dosing regimen for clinical studies to assess the antipsychotic-like efficacy of mGlu ${ }_{5}$ PAMs, doses chosen do not need to achieve full RO in humans.

In conclusion, the current findings support the utility of $\left[{ }^{18} \mathrm{~F}\right] \mathrm{FPEB}$ and PET imaging as a useful biomarker for the development of $\mathrm{mGlu}_{5}$ PAMs. These studies support a close relationship between in vivo RO and efficacy and suggest that RO of $\mathrm{mGlu}_{5}$ can be used as a valuable tool to accurately predict doses of PAMs required for antipsychotic efficacy. However, subtle differences in ligand docking suggested by recent structural and modeling studies can lead to fundamental differences in ligand interactions of $\mathrm{mGlu}_{5}$ modulators, even for modulators that are closely related structural analogs. Detailed molecular pharmacology analysis is essential for establishing a fully competitive interaction of two ligands before advancing to in vivo occupancy studies.

\section{FUNDING AND DISCLOSURE}

Dr Rook's work has been funded by NIH, Alzheimer's Drug Discovery Foundation, and Thome Alzheimer's
Disease Drug Discovery Foundation. Dr Felts has received compensation from Seaside Therapeutics. Dr Stauffer's work has been funded by the NIH and by an industry sponsored research contract from Janssen. He is an inventor on patents that protect different classes of $\mathrm{mGlu}_{5}$ PAMs. Dr Emmitte's work has been funded by the NIH and collaborative research agreements with Seaside Therapeutics. He is an inventor on patents that protect different classes of $\mathrm{mGlu}_{5}$ NAMs. Dr Kessler's work has been funded by Novo Nordisc and by the NIH. In addition, he is a stockholder in PHarmRx Therapeutics and a consultant for Shire Pharmaceuticals. Dr Niswender's work has been funded by the NIH, the International Rett Syndrome Foundation and Autism Speaks. She has received licensing royalties from Johnson and Johnson, Bristol-Myers Squibb, and Seaside Therapeutics, and is an inventor on patents that protect different classes of metabotropic glutamate and muscarinic receptor allosteric modulators. Dr Daniels' work has been funded in part by the NIH and the Molecular Libraries Probe Production Centers Network. He has received compensation from Johnson and Johnson, Bristol-Myers Squibb, Seaside Therapeutics and as a member of the scientific advisory board of the SigmaAldrich company and through consulting for Agios Pharmaceuticals Company and the Michael J. Fox Foundation. He is an inventor on patents that protect different classes of metabotropic glutamate and muscarinic receptor allosteric modulators. Dr Jones received research support from Bristol-Myers Squibb, Johnson and Johnson, and AstraZeneca. Dr Jones also received funding through the Michael J. Fox Foundation, the Barrus Foundation, and NIH. She is an inventor on patents that protect different classes of metabotropic glutamate and muscarinic receptor allosteric modulators. Dr Lindsley's work has been funded by the NIH, Bristol-Myers Squibb, AstraZeneca, Michael J. Fox Foundation, as well as Seaside Therapeutics. He has consulted for AbbVie and received compensation. He is an inventor on patents that protect different classes of metabotropic glutamate and muscarinic receptor allosteric modulators. Dr Conn has been funded by NIH, Johnson and Johnson, AstraZeneca, Bristol-Myers Squibb, Michael J. Fox Foundation, and Seaside Therapeutics. He has consulted over the past 3 years for Pfizer, Cambridge, and Millipore Corporation, and received compensation. Over the past 3 years he has served on the Scientific Advisory Boards and received compensation from Seaside Therapeutics, Michael J. Fox Foundation, Stanley Center for Psychiatric Research Broad Institute (MIT/Harvard), Karuna Pharmaceuticals, Lieber Institute for Brain Development Johns Hopkins University, Clinical Mechanism and Proof of Concept Consortium, and Neurobiology Foundation for Schizophrenia and Bipolar Disorder He is an inventor on patents that protect different classes of metabotropic glutamate and muscarinic receptor allosteric modulators. Dr Tantawy, Dr Ansari, and Dr Felts declare no potential conflict of interest.

\section{ACKNOWLEDGEMENTS}

We would like to thank George Wilson, Zou Yue and Ya Zhou for their technical expertise. This work was supported by NIH R01 MH062646 (PJC), R01 NS031373 (PJC) and F32 MH088234 (JMR). 


\section{REFERENCES}

Ametamey SM, Kessler LJ, Honer M, Wyss MT, Buck A, Hintermann S et al (2006). Radiosynthesis and preclinical evaluation of $11 \mathrm{C}-\mathrm{ABP} 688$ as a probe for imaging the metabotropic glutamate receptor subtype 5. J Nucl Med 47: 698-705.

Anderson JJ, Bradbury MJ, Giracello DR, Chapman DF, Holtz G, Roppe J et al (2003). In vivo receptor occupancy of mGlu5 receptor antagonists using the novel radioligand [3H]3-methoxy5-(pyridin-2-ylethynyl)pyridine). Eur J Pharmacol 473: 35-40.

Andersson JD, Seneca N, Truong P, Wensbo D, Raboisson P, Farde L et al (2013). Palladium mediated (1)(1)C-cyanation and characterization in the non-human primate brain of the novel mGluR5 radioligand [(1)(1)C]AZD9272. Nucl Med Biol 40: 547-553.

Ansari MS, Rook JM, Conn PJ, Felts AS, Lindsley CW, Baldwin R et al (2010). Microwave synthesis of [18F]FPEB in a semiautomated synthesis module. Society of Nuclear Medicine Annual Meeting Publication No.: 141.

Berg D, Godau J, Trenkwalder C, Eggert K, Csoti I, Storch A et al (2011). AFQ056 treatment of levodopa-induced dyskinesias: results of 2 randomized controlled trials. Mov Disord 26: 1243-1250.

Bergstrom M, Hargreaves RJ, Burns HD, Goldberg MR, Sciberras D, Reines SA et al (2004). Human positron emission tomography studies of brain neurokinin 1 receptor occupancy by aprepitant. Biol Psychiatry 55: 1007-1012.

Castner SA, Murthy NV, Ridler K, Herdon H, Roberts BM, Weinzimmer DP et al (2014). Relationship between glycine transporter 1 inhibition as measured with positron emission tomography and changes in cognitive performances in nonhuman primates. Neuropsychopharmacology (e-pub ahead of print).

Chen Y, Goudet C, Pin JP, Conn PJ (2008). N-\{4-Chloro-2-[(1,3dioxo-1,3-dihydro-2H-isoindol-2-yl)methyl]phenyl $\}$-2-hydroxybenzamide (CPPHA) acts through a novel site as a positive allosteric modulator of group 1 metabotropic glutamate receptors. $\mathrm{Mol}$ Pharmacol 73: 909-918.

Chen Y, Nong Y, Goudet C, Hemstapat K, de Paulis T, Pin JP et al (2007). Interaction of novel positive allosteric modulators of metabotropic glutamate receptor 5 with the negative allosteric antagonist site is required for potentiation of receptor responses. Mol Pharmacol 71: 1389-1398.

Conn PJ, Lindsley CW, Jones CK (2009). Activation of metabotropic glutamate receptors as a novel approach for the treatment of schizophrenia. Trends Pharmacol Sci 30: 25-31.

Conn PJ, Lindsley CW, Meiler J, Niswender CM (2014). Opportunities and challenges in discovery of allosteric modulators of GPCRs for treatment of CNS disorders. Nat Rev Drug Discov 13: 692-708.

Conn PJ, Stauffer SR, Zhou S, Manka J, Williams R, Noetzel MJ et al (2011). Allosteric modulators of metabotropic glutamate receptor 5 for treatment of Schizophrenia. 7th International Metabotropic Glutamate Receptors Meeting, 6 October 2011, Taormina, Italy.

Cosford ND, Roppe J, Tehrani L, Schweiger EJ, Seiders TJ, Chaudary A et al (2003a). [3H]-methoxymethyl-MTEP and [3H]-methoxy-PEPy: potent and selective radioligands for the metabotropic glutamate subtype 5 (mGlu5) receptor. Bioorg Med Chem Lett 13: 351-354.

Cosford ND, Tehrani L, Roppe J, Schweiger E, Smith ND, Anderson J et al (2003b). 3-[(2-Methyl-1,3-thiazol-4-yl)ethynyl]-pyridine: a potent and highly selective metabotropic glutamate subtype 5 receptor antagonist with anxiolytic activity. J Med Chem 46: 204-206.

Dore AS, Okrasa K, Patel JC, Serrano-Vega M, Bennett K, Cooke RM et al (2014). Structure of class C GPCR metabotropic glutamate receptor 5 transmembrane domain. Nature 511: $557-562$.
Emmitte KA (2013). mGlu5 negative allosteric modulators: a patent review (2010-2012). Expert Opin Ther Pat 23: 393-408.

Facklam M, Schoch P, Bonetti EP, Jenck F, Martin JR, Moreau JL et al (1992). Relationship between benzodiazepine receptor occupancy and functional effects in vivo of four ligands of differing intrinsic efficacies. J Pharmacol Exp Ther 261: 1113-1121.

Felts AS, Rodriguez AL, Morrison RD, Venable DF, Manka JT, Bates BS et al (2013). Discovery of VU0409106: A negative allosteric modulator of mGlu5 with activity in a mouse model of anxiety. Bioorg Med Chem Lett 23: 5779-5785.

Gregory KJ, Nguyen ED, Malosh C, Mendenhall JL, Zic JZ, Bates BS et al (2014). Identification of specific ligand-receptor interactions that govern binding and cooperativity of diverse modulators to a common metabotropic glutamate receptor 5 allosteric site. ACS Chem Neurosci 5: 282-295.

Gregory KJ, Nguyen ED, Reiff SD, Squire EF, Stauffer SR, Lindsley CW et al (2013). Probing the metabotropic glutamate receptor 5 (mGlu(5)) positive allosteric modulator (PAM) binding pocket: discovery of point mutations that engender a 'molecular switch' in PAM pharmacology. Mol Pharmacol 83: 991-1006.

Gregory KJ, Noetzel MJ, Rook JM, Vinson PN, Stauffer SR, Rodriguez AL et al (2012). Investigating metabotropic glutamate receptor 5 allosteric modulator cooperativity, affinity, and agonism: enriching structure-function studies and structureactivity relationships. Mol Pharmacol 82: 860-875.

Hamill TG, Krause S, Ryan C, Bonnefous C, Govek S, Seiders TJ et al (2005). Synthesis, characterization, and first successful monkey imaging studies of metabotropic glutamate receptor subtype 5 (mGluR5) PET radiotracers. Synapse 56: 205-216.

Jacquemont S, Curie A, des Portes V, Torrioli MG, Berry-Kravis E, Hagerman RJ et al (2011). Epigenetic modification of the FMR1 gene in fragile $\mathrm{X}$ syndrome is associated with differential response to the mGluR5 antagonist AFQ056. Sci Transl Med 3: 64 ra61.

Kola I (2008). The state of innovation in drug development. Clin Pharmacol Ther 83: 227-230.

Loening AM, Gambhir SS (2003). AMIDE: a free software tool for multimodality medical image analysis. Mol Imaging 2: 131-137.

Logan J (2000). Graphical analysis of PET data applied to reversible and irreversible tracers. Nucl Med Biol 27: 661-670.

Logan J, Fowler JS, Volkow ND, Wang GJ, Ding YS, Alexoff DL (1996). Distribution volume ratios without blood sampling from graphical analysis of PET data. J Cereb Blood Flow Metab 16: 834-840.

Majo VJ, Prabhakaran J, Mann JJ, Kumar JS (2013). PET and SPECT tracers for glutamate receptors. Drug Discov Today 18: 173-184.

Mu L, Schubiger PA, Ametamey SM (2010). Radioligands for the PET imaging of metabotropic glutamate receptor subtype 5 (mGluR5). Curr Top Med Chem 10: 1558-1568.

Noetzel MJ, Rook JM, Vinson PN, Cho HP, Days E, Zhou Y et al (2012). Functional impact of allosteric agonist activity of selective positive allosteric modulators of metabotropic glutamate receptor subtype 5 in regulating central nervous system function. Mol Pharmacol 81: 120-133.

Pagano A, Ruegg D, Litschig S, Stoehr N, Stierlin C, Heinrich M et al (2000). The non-competitive antagonists 2-methyl-6(phenylethynyl)pyridine and 7-hydroxyiminocyclopropan[b]chromen-1a-carboxylic acid ethyl ester interact with overlapping binding pockets in the transmembrane region of group I metabotropic glutamate receptors. $J$ Biol Chem 275: 33750-33758.

Patel S, Ndubizu O, Hamill T, Chaudhary A, Burns HD, Hargreaves R et al (2005). Screening cascade and development of potential Positron Emission Tomography radiotracers for mGluR5: in vitro and in vivo characterization. Mol Imaging Biol 7: 314-323. 
Raskin A, Casdin E (2011). The Dawn of Molecular Medicine. The Transformation of Medicine and Its Consequences for Investors. http://www.alliancebernstein.com. AllianceBernstein L.P. Vol Research.

Rodriguez AL, Grier MD, Jones CK, Herman EJ, Kane AS, Smith $\mathrm{RL}$ et al (2010). Discovery of novel allosteric modulators of metabotropic glutamate receptor subtype 5 reveals chemical and functional diversity and in vivo activity in rat behavioral models of anxiolytic and antipsychotic activity. Mol Pharmacol 78: $1105-1123$.

Rodriguez AL, Nong Y, Sekaran NK, Alagille D, Tamagnan GD, Conn PJ (2005). A close structural analog of 2-methyl-6(phenylethynyl)-pyridine acts as a neutral allosteric site ligand on metabotropic glutamate receptor subtype 5 and blocks the effects of multiple allosteric modulators. Mol Pharmacol 68: 1793-1802.

Rook JM, Noetzel MJ, Pouliot WA, Bridges TM, Vinson PN, Cho HP et al (2012). Unique signaling profiles of positive allosteric modulators of metabotropic glutamate receptor subtype 5 determine differences in in vivo activity. Biol Psychiatry 73: 501-509.

Rook JM, Tantawy MN, Ansari MS, Zhou Y, Morrison RD, Stauffer SR et al (2011). Relationship between in vivo receptor occupancy and efficacy of novel metabotropic glutamate receptor subtype 5 allosteric modulators with different in vitro profiles of activity at mGlu5. American College of Neuropsychopharmacology 50th Annual Meeting. Waikoloa Beach, Hawaii.

Rubins DJ, Melega WP, Lacan G, Way B, Plenevaux A, Luxen A et al (2003). Development and evaluation of an automated atlas-based image analysis method for microPET studies of the rat brain. Neuroimage 20: 2100-2118.

Russell D (2014). A PET brain imaging study of mGluR5 in subjects with neuropsychiatric conditions (FPEB). ClinicalTrials.gov Vol 2014.

Shetty HU, Zoghbi SS, Simeon FG, Liow JS, Brown AK, Kannan P et al (2008). Radiodefluorination of 3-fluoro-5-(2-(2-[18F](fluoromethyl)-thiazol-4-yl)ethynyl)benzonitrile ([18F]SP203), a radioligand for imaging brain metabotropic glutamate subtype-5 receptors with positron emission tomography, occurs by glutathionylation in rat brain. J Pharmacol Exp Ther 327: 727-735.

Wang JQ, Tueckmantel W, Zhu A, Pellegrino D, Brownell AL (2007). Synthesis and preliminary biological evaluation of 3-[(18)F]fluoro-5-(2-pyridinylethynyl)benzonitrile as a PET radiotracer for imaging metabotropic glutamate receptor subtype 5. Synapse 61: 951-961.

Williams R, Manka JT, Rodriguez AL, Vinson PN, Niswender CM, Weaver CD et al (2011). Synthesis and SAR of centrally active mGlu5 positive allosteric modulators based on an aryl acetylenic bicyclic lactam scaffold. Bioorg Med Chem Lett 21: 1350-1353.

Wong DF, Waterhouse R, Kuwabara H, Kim J, Brasic JR, Chamroonrat $\mathrm{W}$ et al (2013). 18F-FPEB, a PET radiopharmaceutical for quantifying metabotropic glutamate 5 receptors: a first-in-human study of radiochemical safety, biokinetics, and radiation dosimetry. J Nucl Med 54: 388-396.

Wu H, Wang C, Gregory KJ, Han GW, Cho HP, Xia Y et al (2014). Structure of a class C GPCR metabotropic glutamate receptor 1 bound to an allosteric modulator. Science 344: 58-64. 